\title{
BMJ A retrospective cross-sectional study of OPOn risk factors and clinical spectrum of children admitted to hospital with pandemic H1N1 influenza as compared to influenza A
}

\author{
Shaun K Morris, ${ }^{1}$ Patricia Parkin, ${ }^{2}$ Michelle Science, ${ }^{1}$ Padmaja Subbarao, ${ }^{3}$ \\ Yvonne Yau, ${ }^{4}$ Sean O'Riordan, ${ }^{5}$ Michelle Barton, ${ }^{1}$ Upton D Allen, ${ }^{1}$ Dat $\operatorname{Tran}^{1}$
}

To cite: Morris SK, Parkin P, Science M, et al. A retrospective cross-sectional study of risk factors and clinical spectrum of children admitted to hospital with pandemic H1N1 influenza as compared to influenza A. BMJ Open 2012;2:e000310. doi:10.1136/

bmjopen-2011-000310

- Prepublication history and additional table for this paper is available online. To view these files please visit the journal online (http://dx.doi. org/10.1136/

bmjopen-2011-000310).

Received 12 October 2011 Accepted 26 January 2012

This final article is available for use under the terms of the Creative Commons Attribution Non-Commercial 2.0 Licence; see http://bmjopen.bmj.com

For numbered affiliations see end of article.

Correspondence to

Dr Dat Tran;

dat.tran@sickkids.ca

\section{ABSTRACT}

Objective: To compare risk factors for severe disease as measured by admission to hospital and intensive care unit (ICU) and other clinical outcomes in children with pandemic H1N1 (pH1N1) versus those with seasonal influenza.

Design: Retrospective analysis of children admitted to hospital with pH1N1 versus seasonal influenza $\mathrm{A}$.

Setting: Canadian tertiary referral children's hospital.

Participants: All laboratory-identified cases of pH1N1 in children younger than 18 years admitted to hospital in $2009(n=176)$ and all seasonal influenza A cases admitted to hospital from influenza seasons 2004-2005 to 2008-2009 $(n=200)$. Children with onset of symptoms more than 3 days after admission were excluded.

\section{Primary and secondary outcome}

measures: Primary outcomes include admission to hospital and ICU and need for mechanical ventilation. Secondary outcomes include length of stay in hospital and duration of supplemental oxygen requirement.

Results: Children admitted with pH1N1 were older than seasonal influenza $A$ admissions (hospital admission: 6.5 vs 3.3 years, $p<0.01$; ICU admission: 7.3 vs 3.6 years, $p=0.02$ ). Children hospitalised with $\mathrm{pH} 1 \mathrm{~N} 1$ were more likely to have a pre-existing diagnosis of asthma ( $15 \%$ vs $5 \%, p<0.01)$; however, there was no difference in the severity of pre-existing asthma between the two groups. After controlling for obesity, asthma (OR $4.59,95 \% \mathrm{Cl} 1.42$ to 14.81 ) and age $\geq 5$ years (OR 2.87, $95 \% \mathrm{Cl} 1.60$ to 5.16 ) were more common risk factors in admitted children with pH1N1. Asthma was a significant predictor of the need for intensive care in patients with pH1N1 (OR 4.56, 95\% Cl 1.16 to 17.89) but not in patients with seasonal influenza $A$.

Conclusion: While most pH1N1 cases presented with classic influenza-like symptoms, risk factors for severe pH1N1 disease differed from seasonal influenza A. Older age and asthma were associated with increased admission to hospital and ICU for children with pH1N1.

\section{ARTICLE SUMMARY}

Article focus

- Young age and underlying medical conditions have traditionally been considered risk factors for severe influenza in children.

- Children admitted with pH1N1 influenza are more likely to have asthma; however, the impact of asthma severity is unknown.

Key messages

- The presence of asthma and increased age, but not severity of asthma, were more common risk factors for hospitalisation with severe H1N1 influenza than with seasonal influenza $A$.

- These results suggest that in future pandemics, certain high-risk groups may be more adversely affected than expected with seasonal influenza.

- Treatment of pH1N1 influenza with oseltamivir did not appear to be associated with differing outcomes or severity of disease.

Strengths and limitations of this study

- The strength of this study is that it compares a large number of children admitted with microbiologically confirmed pH1N1 to those admitted over 5 years with seasonal influenza A. For each admitted child with suspected asthma, at least two physicians reviewed the case to confirm a diagnosis of pre-existing asthma and to grade the asthma as mild, moderate or severe.

- The main limitations of this study include its retrospective design, single-centre site, the inability to calculate population-based rates and that the number of admitted patients with asthma, particularly to ICU, was small.

\section{INTRODUCTION}

In a large global pooled analysis of patients of all ages, the risk factors for severe pandemic H1N1 ( $\mathrm{pH} 1 \mathrm{~N} 1$ ) disease have been found to have some notable differences from seasonal 
influenza, including younger age, obesity and pregnancy. ${ }^{1}$ In the paediatric population, infants and young children have traditionally been considered at risk for severe seasonal influenza. ${ }^{23}$ However, recently published paediatric studies suggest that while most cases of pH1N1 are relatively mild, older children, especially those suffering from asthma and obesity, may be at higher risk for severe disease. Rates of paediatric intensive care admission, mechanical ventilation, and mortality associated with $\mathrm{pH} 1 \mathrm{~N} 1$ may be higher than those associated with seasonal influenza. ${ }^{4-7}$

A previous study from our centre following the first wave of the pandemic found that children admitted with pH1N1 were significantly older and more likely to have asthma than those admitted with seasonal influenza A. ${ }^{8}$ In late 2009, a second wave of pH1N1 resulted in more admissions to our hospital. The increase in $\mathrm{pH} 1 \mathrm{~N} 1$ cases allowed us to verify the findings of our initial study and identify independent risk factors for admission to the intensive care unit (ICU) among pH1N1 and seasonal influenza hospitalised cases through multivariable analyses. Finally, we wanted to understand how differences in diagnostic methods and treatment between $\mathrm{pH} 1 \mathrm{~N} 1$ and seasonal influenza might affect outcomes. Thus, our primary goals in this study were to compare the ageadjusted proportions of children with asthma admitted to hospital and the ICU with pH1N1 relative to those admitted with seasonal influenza and to determine whether age and asthma are independent predictors of ICU admission in pH1N1 as well as seasonal influenza infection. Secondary goals were to describe clinical features, other markers of illness severity and effect of antiviral therapy and diagnostic methods on outcomes in children with $\mathrm{pH} 1 \mathrm{~N} 1$.

\section{DESIGN}

We identified and reviewed health records of all laboratory-confirmed cases of $\mathrm{pH} 1 \mathrm{~N} 1$ in children younger than 18 years admitted in 2009 to The Hospital for Sick Children (SickKids), a large paediatric referral hospital in Toronto, Canada, with over 14000 admissions per year. ${ }^{9}$ Cases were identified through a review of microbiology laboratory records. We compared children admitted with pH1N1 to those admitted with seasonal influenza A during the 2004-2005 through 2008-2009 influenza seasons. In order to exclude potential hospital-acquired infections, we excluded any children who developed influenza-like symptoms on or after the third day of admission. Testing was done at the clinical discretion of the attending physician. All patients with influenza-like illness were initially screened for influenza by direct immunofluorescence assay (DFA). During the first wave of the pandemic, all inpatient respiratory samples were tested using reverse transcription PCR with primers developed by the National Microbiology Laboratory, Winnipeg, Manitoba, Canada. ${ }^{10}$ During the second wave, all inpatient respiratory samples were tested with a commercial realtime reverse transcription PCR kit (RTPCR Kit 1.0; Astra
Diagnostics, Hamburg, Germany). Seasonal influenza cases were identified through DFA and/or viral culture. Two physicians (MS and DT) reviewed each potential case of asthma to confirm the diagnosis and determine severity (web table). Any discrepancies were adjudicated by an asthma specialist (PS).

Comparisons were made between the $\mathrm{pH} 1 \mathrm{~N} 1$ and seasonal influenza A groups and between the first and second waves of pH1N1. Differences in normally distributed continuous variables were analysed using Student's t test. Comparisons of skewed data (length of stay and age) were analysed using non-parametric Mann-Whitney and Kruskal-Wallis methods. The $\chi^{2}$ or Fisher's exact test was used to compare categorical variables between groups and as a test of heterogeneity among multiple proportions. We performed multivariable logistic regression to (1) adjust for the potential confounding effect of age (as a continuous variable and categorical variable) on asthma as a risk factor in comparing the severity of $\mathrm{pH} 1 \mathrm{~N} 1$ and seasonal influenza A and (2) construct models of risk for ICU admission in pH1N1 and seasonal influenza A infection that included age (as a continuous variable and categorical variable), asthma and obesity as independent variables. All statistical analysis was performed using Stata SE V.10. ${ }^{11}$

\section{RESULTS}

One hundred and seventy-nine children with pH1N1 were admitted in 2009 in two waves (May to July 2009 $\mathrm{n}=58$, September to December $2009 \mathrm{n}=118$ ) (figure 1), of whom three were excluded because the onset of symptoms was more than 3 days after admission, leaving a total of 176 cases included for analysis. Two hundred children were admitted to hospital with seasonal influenza A over five seasons (2004-2005, $\mathrm{n}=46$; 2005-2006, $\mathrm{n}=26 ; \quad 2006-2007, \quad \mathrm{n}=36 ; \quad 2007-2008, \quad \mathrm{n}=56$; 2008-2009, $n=36$ ). There were no differences across the years of seasonal influenza cases in terms of demographic characteristics, underlying risk factors or outcomes (data not shown).

\section{Demographic characteristics}

Characteristics of children with $\mathrm{pH} 1 \mathrm{~N} 1$ and seasonal influenza are shown in table 1. Children with $\mathrm{pH} 1 \mathrm{~N} 1$ were significantly older than those with seasonal influenza A (6.5 vs 3.3 years, $\mathrm{p}<0.01)$. The proportion of children 5 years and older was higher in pH1N1 $(61 \%$ vs $36 \%, \mathrm{p}<0.01)$, whereas the proportion under 2 years was higher in seasonal influenza A $(37 \%$ vs $18 \%, \mathrm{p}<0.01)$. Children admitted to ICU with $\mathrm{pH} 1 \mathrm{~N} 1$ were older than those with seasonal influenza A ( 7.3 vs 3.6 years, $p=0.02$ ).

\section{Disease severity}

Requirement and duration of oxygen therapy, ICU admission, mechanical ventilation and total length of hospital stay are shown in table 1. Fifty-nine (34\%) patients admitted with $\mathrm{pH} 1 \mathrm{N1}$ required oxygen supplementation. Thirty-two (18\%) children with pH1N1 


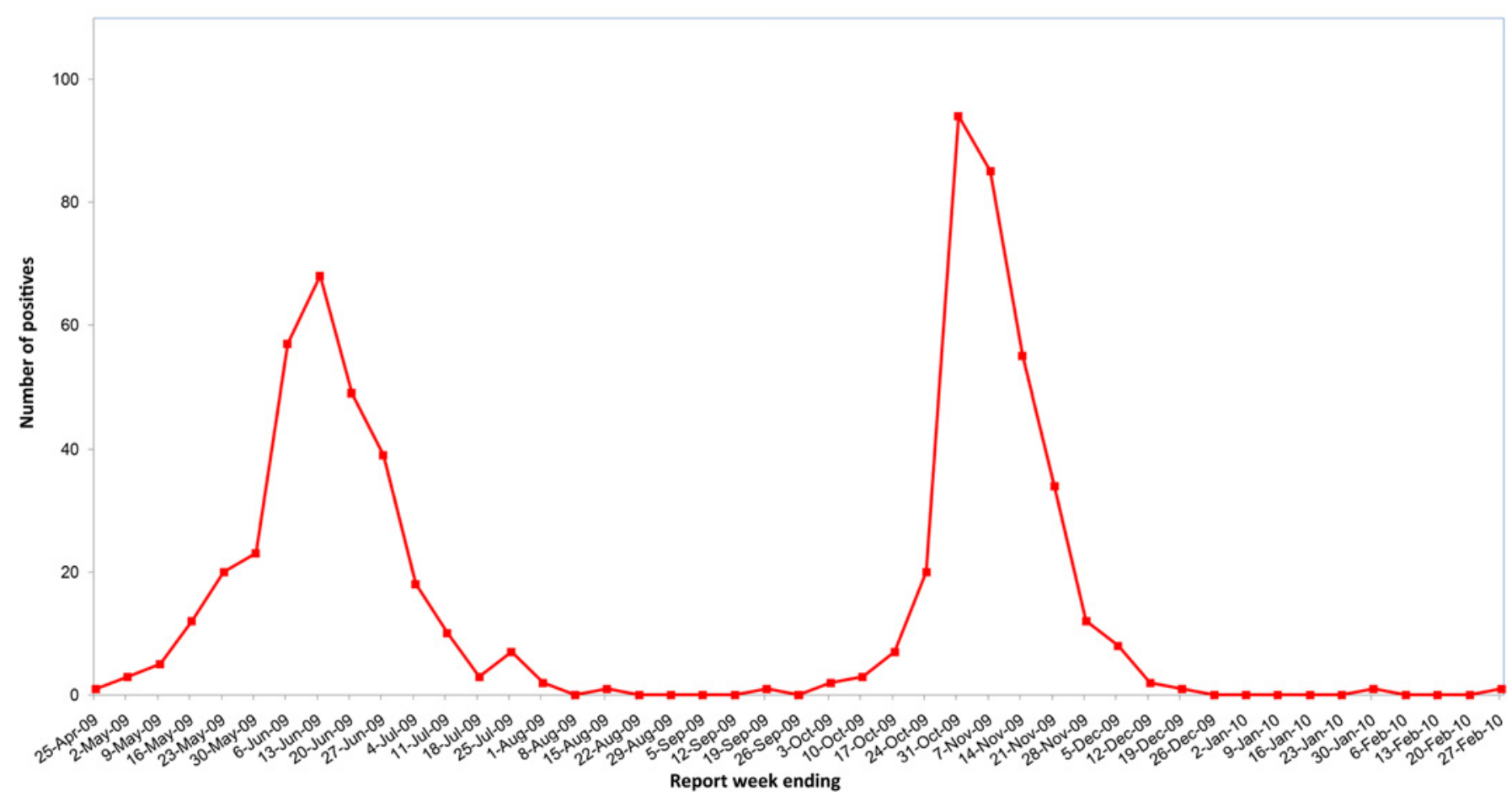

Figure 1 Number of pH1N1 detected, SickKids, by report week, 2009-2010.

required admission to ICU and of these, 18 (56\%) required mechanical ventilation. There was no difference in ICU admission or need for mechanical ventilation between $\mathrm{pH} 1 \mathrm{~N} 1$ and seasonal influenza A. More children admitted during the first wave required oxygen than those admitted during the second wave $(47 \%$ vs $28 \%, \mathrm{p}=0.01)$. When examining only children who did not receive antiviral therapy, the difference in oxygen use between waves 1 and 2 remained significant $(48 \%$ vs $19 \%, \mathrm{p}=0.03)$. None of the patients with $\mathrm{pH} 1 \mathrm{~N} 1 \mathrm{died}$.

\section{Clinical and laboratory characteristics}

Most $\mathrm{pH} 1 \mathrm{~N} 1$ cases presented with fever and cough. More than one-third had gastrointestinal symptoms (table 2). The laboratory results of children admitted with pH1N1 are shown in table 3. Four patients had positive blood cultures during their admission (Streptococcus pneumoniae (two patients), Viridans group Streptococcus (one patient), Pseudomonas aeruginosa (one patient)).

\section{Risk factors}

Children with pH1N1 compared to those with seasonal influenza A were more likely to have a history of asthma ( $15 \%$ vs $5 \%, \mathrm{p}<0.01)$; however, there was no difference in the severity of asthma between the two groups (table $4)$. Cardiac disease $(11 \%$ vs $4 \%, \mathrm{p}=0.02)$ and age under 2 years with no other risk factors ( $18 \%$ vs $9 \%, \mathrm{p}=0.02)$ were more common in children hospitalised with seasonal influenza A. In patients requiring intensive care, history of asthma was more common in pH1N1 than in seasonal influenza A; however, this difference did not reach statistical significance $(19 \%$ vs $3 \%, p=0.10)$. In a multivariable analysis including obesity, age category and asthma, both age $\geq 5$ (with age $<2$ as reference) (OR 2.87, 95\% CI 1.60 to 5.16) and history of asthma (OR $4.59,95 \%$ CI 1.42 to 14.81 ) were more common as risk factors in admitted children with pH1N1 compared to seasonal influenza A. In the same analysis but using age as a continuous rather than categorical variable, asthma remained more common as a risk factor in pH1N1 (OR 8.77, 95\% CI 1.85 to 41.52). Table 5 displays multivariable logistic regression analyses for predictors of ICU admission with pH1N1 and with seasonal influenza A infection. In multivariable models including obesity, age category and underlying asthma as independent variables, asthma was a significant predictor of the need for intensive care with $\mathrm{pH} 1 \mathrm{~N} 1$ infection (OR $4.56,95 \%$ CI 1.16 to 17.89 ) but not with seasonal influenza A infection. When the multivariable models included age as a continuous instead of categorical variable, underlying asthma remained a significant predictor of the need for ICU care with $\mathrm{pH} 1 \mathrm{~N} 1$ infection (OR 5.22, 95\% CI 1.23 to 22.08). In children with asthma, $29 \%$ of those with $\mathrm{pH} 1 \mathrm{~N} 1$ versus $33 \%$ of those with seasonal influenza A presented with acute wheeze $(p=0.81)$. In children without underlying asthma, there was no difference in presentation with acute wheeze in those with pH1N1 (15\%) and those with seasonal influenza A $(12 \%)(\mathrm{p}=0.51)$.

\section{Diagnosis and management}

At our institution, seasonal influenza was diagnosed by DFA supplemented with viral culture, whereas cases positive by DFA for $\mathrm{pH} 1 \mathrm{~N} 1$ required confirmation by 
Table 1 Demographic and clinical characteristics of pH1N1 and seasonal influenza

\begin{tabular}{|c|c|c|c|c|c|c|}
\hline \multirow[b]{2}{*}{ Characteristic } & \multicolumn{3}{|c|}{ pH1N1 wave 1 versus wave 2} & \multicolumn{3}{|c|}{ pH1N1 versus seasonal influenza } \\
\hline & $\begin{array}{l}\text { pH1N1 wave } \\
1(n=58)\end{array}$ & $\begin{array}{l}\text { pH1N1 wave } \\
2(n=118)\end{array}$ & p Value & $\begin{array}{l}\text { pH1N1 total } \\
(n=176)\end{array}$ & $\begin{array}{l}\text { Seasonal, } \\
(n=200)\end{array}$ & p Value \\
\hline Sex, male, n (\%) & $35(60)$ & $72(61)$ & 0.93 & $107(61)$ & $108(54)$ & 0.18 \\
\hline Age, years, median (IQR) & $6.4(3.4-10.1)$ & $6.5(2.9-11.4)$ & 0.81 & $6.5(3.0-10.6)$ & $3.3(1.4-7.8)$ & $<0.01$ \\
\hline \multicolumn{7}{|l|}{ Age group, years, $\mathrm{n}(\%)$} \\
\hline$<2$ & $8(14)$ & $23(19)$ & 0.35 & 31 (18) & 74 (37) & $<0.01$ \\
\hline 2 to $<5$ & $13(22)$ & $24(20)$ & 0.75 & $37(21)$ & $54(27)$ & 0.18 \\
\hline$\geq 5$ & $37(64)$ & $71(60)$ & 0.64 & $108(61)$ & $72(36)$ & $<0.01$ \\
\hline \multicolumn{7}{|l|}{ Admitted to ICU } \\
\hline No. (\%) of children & $12(21)$ & $20(17)$ & 0.36 & $32(18)$ & $31(15)$ & 0.49 \\
\hline Age, years, median (IQR) & $5.8(3.2-7.3)$ & $9.2(5.4-11.4)$ & 0.13 & $7.3(4.0-10.6)$ & $3.6(1.5-9.7)$ & 0.02 \\
\hline \multicolumn{7}{|c|}{ Required mechanical ventilation } \\
\hline No. (\%) of children & $7(12)$ & $11(9)$ & 0.57 & $18(10)$ & $19(10)$ & 0.81 \\
\hline $\begin{array}{l}\text { No. }(\%) \text { of children } \\
\text { admitted to ICU }\end{array}$ & $7(58)$ & $11(55)$ & 0.85 & $18(56)$ & $19(61)$ & 0.69 \\
\hline \multicolumn{7}{|l|}{ Required supplemental oxygen } \\
\hline No. (\%) of children & $26(47)$ & $33(28)$ & 0.01 & $59(34)$ & NA & NA \\
\hline $\begin{array}{l}\text { Duration of oxygen, days, } \\
\text { median (IQR) }\end{array}$ & $4(2-6)$ & $3(2-7)$ & 0.73 & $3(2-6)$ & NA & NA \\
\hline \multicolumn{7}{|c|}{ Length of stay, days, median (IQR) } \\
\hline In hospital & $4(2-6)$ & $3(2-5)$ & 0.06 & $3(2-5)$ & $4(2-7)$ & 0.12 \\
\hline In ICU & $3.5(2.5-17)$ & $2(1.5-5)$ & 0.08 & $3(2-8)$ & $2(1-5)$ & 0.24 \\
\hline Antiviral therapy, $\mathrm{n}(\%)$ & $11(19)$ & $97(82)$ & $<0.01$ & $108(61)$ & $16(8)$ & $<0.01$ \\
\hline
\end{tabular}

Bold values are significantly different as defined by a $p$ value $<0.05$.

ICU, intensive care unit; $\mathrm{pH} 1 \mathrm{~N} 1$, pandemic $\mathrm{H} 1 \mathrm{~N} 1$.

PCR. To assess the potential impact of differing diagnostic methods, we re-analysed all cases restricting solely to those positive by DFA. The only changes from the previously presented results were that the length of stay in hospital was longer in seasonal influenza A (median 3.5 vs 3 days, $p=0.03$ ) and that underlying chronic lung disease (excluding asthma) was no longer significantly more common in those admitted to ICU with seasonal influenza A $(p=0.09)$.

Children with $\mathrm{pH} 1 \mathrm{~N} 1$ were more likely to receive antiviral therapy $(61 \%$ vs $8 \%, \mathrm{p}<0.01)$. There were significant changes in how pH1N1 was managed between waves; $19 \%$ of children received antiviral therapy during wave 1 compared to $82 \%$ in wave $2(p<0.01)$. However, when comparing all children with $\mathrm{pH} 1 \mathrm{~N} 1$ who received antiviral therapy to those who did not, there were no significant differences in the need for ICU admission (22\% vs $14 \%, \mathrm{p}=0.07)$, mechanical ventilation $(14 \%$ vs $8 \%, \mathrm{p}=0.08$ ) or length of stay in hospital (median duration 3 vs 3 days, $p=0.68$ ). To test if sicker children received antiviral therapy, we compared all available Canadian Triage and Acuity Scores, ${ }^{13}$ a standardised

Table 2 Clinical characteristics of $\mathrm{pH} 1 \mathrm{~N} 1$ and seasonal influenza by age category

\begin{tabular}{|c|c|c|c|c|c|c|c|c|}
\hline & \multicolumn{4}{|c|}{ pH1N1 symptoms, n (\%) } & \multicolumn{4}{|c|}{ Seasonal influenza symptoms, $\mathbf{n}(\%)$} \\
\hline & $\begin{array}{l}0 \text { to } \\
<2 \text { years, } \\
n(\%)\end{array}$ & $\begin{array}{l}2 \text { to } \\
<5 \text { years, } \\
n(\%)\end{array}$ & $\begin{array}{l}\geq 5 \text { years, } \\
n(\%)\end{array}$ & $\begin{array}{l}0 \text { to } \\
<18 \text { years, } \\
n(\%)\end{array}$ & $\begin{array}{l}0 \text { to } \\
<2 \text { years, } \\
n(\%)\end{array}$ & $\begin{array}{l}2 \text { to } \\
<5 \text { years, } \\
n(\%)\end{array}$ & $\begin{array}{l}\geq 5 \text { years, } \\
n(\%)\end{array}$ & $\begin{array}{l}0 \text { to } \\
<18 \text { years, } \\
n(\%)\end{array}$ \\
\hline Fever & $31(100)$ & $36(97)$ & $99(92)$ & $166(94)$ & $64(86)$ & $45(83)$ & $59(82)$ & $168(84)$ \\
\hline Cough & $29(94)$ & $34(92)$ & $84(78)$ & $147(84)$ & $34(46)$ & $29(54)$ & $39(54)$ & $102(51)$ \\
\hline Gastrointestinal & $14(45)$ & $16(43)$ & $40(37)$ & $70(40)$ & $13(15)$ & $14(26)$ & $6(8)$ & $33(16)$ \\
\hline Wheeze & $4(13)$ & $8(22)$ & $24(22)$ & $36(20)$ & $11(15)$ & $5(9)$ & $14(19)$ & $30(15)$ \\
\hline Pneumonia & $11(35)$ & $12(32)$ & $29(27)$ & $52(30)$ & $9(12)$ & $8(15)$ & $19(26)$ & 36 (18) \\
\hline Apnoea & $3(10)$ & $3(8)$ & $2(2)$ & $8(5)$ & $0(0)$ & $0(0)$ & $0(0)$ & $0(0)$ \\
\hline Seizure & $2(7)$ & $5(14)$ & $2(2)$ & $9(5)$ & $8(11)$ & $6(11)$ & $4(6)$ & $18(9)$ \\
\hline Encephalopathy & $1(3)$ & $1(3)$ & $2(2)$ & $4(2)$ & $0(0)$ & $0(0)$ & $1(14)$ & $1(0.5)$ \\
\hline Myocarditis & $0(0)$ & $1(3)$ & $1(1)$ & $2(1)$ & $0(0)$ & $0(0)$ & $0(0)$ & $0(0)$ \\
\hline Myositis & $0(0)$ & $0(0)$ & $2(2)$ & $2(1)$ & $0(0)$ & $1(2)$ & $0(0)$ & $1(0.5)$ \\
\hline
\end{tabular}


Table 3 Haematologic laboratory values for children admitted with $\mathrm{pH} 1 \mathrm{~N} 1$ and seasonal influenza

\begin{tabular}{|c|c|c|}
\hline Laboratory value & $\begin{array}{l}\text { pH1N1 } \\
\text { influenza, } \\
\text { n (\%) }\end{array}$ & $\begin{array}{l}\text { Seasonal } \\
\text { influenza, } \\
n(\%)\end{array}$ \\
\hline $\begin{array}{l}\text { White blood cells } \\
\geq 11.0 \times 10^{9} / I\end{array}$ & $50(29)$ & $60(31)$ \\
\hline $\begin{array}{l}\text { White blood cells } \\
<4.0 \times 10^{9} / l\end{array}$ & 33 (19) & $34(17)$ \\
\hline $\begin{array}{l}\text { Absolute neutrophils } \\
>6.6 \times 10^{9} / l\end{array}$ & $59(35)$ & $60(31)$ \\
\hline $\begin{array}{l}\text { Absolute neutrophils } \\
<1.5 \times 10^{9} / l\end{array}$ & $30(18)$ & $36(19)$ \\
\hline $\begin{array}{l}\text { Absolute } \\
\text { lymphocytes } \\
<1.8 \times 10^{9} / \text { I }\end{array}$ & $112(66)$ & $102(53)$ \\
\hline \multicolumn{3}{|c|}{$\begin{array}{l}\text { For pH1N1 influenza, } 174 \text { children had complete blood count and } \\
170 \text { had differential performed. For seasonal influenza, } 196 \\
\text { children had complete blood count and } 193 \text { had differential } \\
\text { performed. } \\
\text { pH1N1, pandemic H1N1. }\end{array}$} \\
\hline
\end{tabular}

measure of disease acuity, between patients with $\mathrm{pH} 1 \mathrm{~N} 1$ who did $(n=65)$ and did not $(n=42)$ receive antiviral therapy and did not find a significant difference between the two groups $(p=0.70)$.

\section{DISCUSSION}

Most cases of $\mathrm{pH} 1 \mathrm{~N} 1$ presented with a classic influenzalike illness, with no convincing evidence that $\mathrm{pH} 1 \mathrm{~N} 1$ was more severe than seasonal influenza. However, the risk factors for admission to hospital and ICU differed between pH1N1 and seasonal influenza. Older age was a greater risk factor for admission to hospital and ICU for $\mathrm{pH} 1 \mathrm{~N} 1$, and asthma was a greater risk factor for hospitalisation for $\mathrm{pH} 1 \mathrm{~N} 1$. These results corroborate earlier research based on fewer cases from our institution $^{8}$ as well as a recent study from Colorado comparing children admitted to hospital with $\mathrm{pH} 1 \mathrm{~N} 1$ to those with 2008-2009 seasonal influenza A or B. ${ }^{14}$ Conversely, underlying cardiac disease in those admitted to hospital and non-asthma chronic lung disease in those admitted to ICU were significantly more common in seasonal influenza A. These results suggest that risk factors for new influenza strains and that high-risk groups during future pandemics may not be simply extrapolated from the experience with seasonal strains. Guidelines from the Public Health Agency of Canada highlighted children $<2$ years of age as a high-risk group for $\mathrm{pH} 1 \mathrm{~N} 1$. $^{15}$ However, our results of a median age of 6.5 years in hospitalised patients with $\mathrm{pH} 1 \mathrm{~N} 1$ are remarkably similar to studies from California ${ }^{16}$ (median age 6 years) and Japan $^{17}$ (median age 7 years). While we found the proportion of hospitalised cases higher in older age categories in $\mathrm{pH} 1 \mathrm{~N} 1$, in the absence of community population-based epidemiological data, we are not able to comment on any differences that may exist in agespecific attack, hospitalisation or ICU admission rates in our study population.

This study was not designed to identify the impact of differing management strategies on severity and outcomes of $\mathrm{pH} 1 \mathrm{~N} 1$. However, in contrast to the first study from our centre, in this study, differences in antiviral use between waves allowed for an interesting natural experiment. Overall, during the first wave, $0 \%$, $46 \%$ and $14 \%$ of children aged younger than 2 years, 2-4 years and 5 years and older, respectively, received oseltamivir. During the second wave, $65 \%, 88 \%$ and $86 \%$

Table 4 Risk factors for admission to hospital and intensive care unit, pH1N1 versus seasonal influenza $A^{*}$

\begin{tabular}{|c|c|c|c|c|c|c|}
\hline \multirow[b]{2}{*}{ Risk factor } & \multicolumn{3}{|c|}{ All children admitted to hospital } & \multicolumn{3}{|c|}{ Children admitted to ICU } \\
\hline & $\begin{array}{l}\text { pH1N1 } \\
(n=176)\end{array}$ & $\begin{array}{l}\text { Seasonal } \\
(n=200)\end{array}$ & p Value & $\begin{array}{l}\text { pH1N1 } \\
(n=32)\end{array}$ & $\begin{array}{l}\text { Seasonal } \\
(n=31)\end{array}$ & p Value $\dagger$ \\
\hline Asthma & $26(15) \neq$ & $9(5)$ & $<0.01$ & $6(19)$ & $1(3)$ & 0.10 \\
\hline Mild asthma & $16(62)$ & $7(78)$ & 0.38 & $4(67)$ & $1(100)$ & 1.00 \\
\hline Moderate asthma & $6(23)$ & $1(11)$ & 0.44 & $1(17)$ & $0(0)$ & 1.00 \\
\hline Severe asthma & $4(15)$ & $1(11)$ & 0.75 & $1(17)$ & $0(0)$ & 1.00 \\
\hline Chronic lung disease & $12(7)$ & $13(7)$ & 0.92 & $0(0)$ & $5(16)$ & 0.02 \\
\hline Obesity§ & $8(7)$ & $14(9)$ & 0.64 & $3(20)$ & $2(9)$ & 0.38 \\
\hline Cardiac disease & $7(4)$ & $21(11)$ & 0.02 & $3(9)$ & $4(12)$ & 0.71 \\
\hline Haemoglobinopathy & $19(11)$ & $22(11)$ & 0.95 & $1(3)$ & $1(3)$ & 0.75 \\
\hline Immunodeficiency & 32 (18) & $42(21)$ & 0.49 & $1(3)$ & $2(3)$ & 0.61 \\
\hline Neurological impairment & $21(12)$ & $26(13)$ & 0.76 & $6(19)$ & $8(26)$ & 0.56 \\
\hline $\begin{array}{l}\text { Age }<2 \text { years and no } \\
\text { other risk factors }\end{array}$ & $16(9)$ & $35(18)$ & 0.02 & $2(6)$ & $4(13)$ & 0.43 \\
\hline \multicolumn{7}{|c|}{$\begin{array}{l}\text { Bold values are significantly different as defined by a } p \text { value }<0.05 \text {. } \\
\text { *Any differences between the numbers presented in table } 4 \text { and those from O'Riordan et } a \beta \text { are the result of a re-assessment of all pH1N1 and } \\
\text { seasonal influenza A cases for this study. } \\
\text { tFisher's exact test used when cell size is small. } \\
\text { fPercentages in parentheses. } \\
\text { \$Obesity was defined according to guidelines from the Centers for Disease Control as a body mass index } \geq 95 \text { th percentile for age in children } \\
2 \text { years and older. }{ }^{12} \text { Obesity could not be calculated for } 45(31 \%) \text { and } 68(54 \%) \text { children } \geq 2 \text { years in the seasonal and pH1N1 groups, } \\
\text { respectively. } \\
\text { pH1N1, pandemic H1N1. }\end{array}$} \\
\hline
\end{tabular}


Table 5 Multivariable regression of asthma, obesity and age category as risk factors for intensive care unit admission with $\mathrm{pH} 1 \mathrm{~N} 1$ and seasonal influenza A

\begin{tabular}{|c|c|c|c|c|c|c|}
\hline \multirow[b]{2}{*}{ Risk factor } & \multicolumn{3}{|c|}{ pH1N1 } & \multicolumn{3}{|c|}{ Seasonal influenza } \\
\hline & OR & Lower $95 \% \mathrm{Cl}$ & Upper $95 \%$ Cl & OR & Lower $95 \% \mathrm{Cl}$ & Upper $95 \% \mathrm{Cl}$ \\
\hline Asthma* & 4.56 & 1.16 & 17.89 & 2.47 & 0.24 & 25.80 \\
\hline Obesity & 4.18 & 0.76 & 22.95 & 1.06 & 0.20 & 5.64 \\
\hline Age 0 to $<2$ years & 1.00 & & & 1.00 & & \\
\hline Age 2 to $<5$ years & 1.70 & 0.30 & 9.48 & 1.40 & 0.44 & 4.44 \\
\hline Age $\geq 5$ years & 0.89 & 0.19 & 4.07 & 0.62 & 0.19 & 1.98 \\
\hline
\end{tabular}

Bold values are significantly different as defined by a $p$ value $<0.05$

${ }^{*}$ Asthma was also more common as a risk factor (OR 5.22, 95\% Cl 1.23 to 22.08) for admission to ICU in pH1N1 compared to seasonal influenza $A$ (with age as continuous variable).

Unadjusted (univariate) ORs for pH1N1: asthma (OR $1.43,95 \% \mathrm{Cl} 0.52$ to 3.91 ), obesity (OR $3.25,95 \% \mathrm{Cl} 0.81$ to 19.69 ), age 0 to $<2$ years (OR 1.00), age 2 to $<5$ years (OR $2.18,95 \% \mathrm{Cl} 0.51$ to 9.26 ), age $\geq 5$ years (OR $2.39,95 \% \mathrm{Cl} 0.66$ to 8.58 ). Unadjusted (univariate) ORs for seasonal influenza A: asthma (OR $0.67,95 \% \mathrm{Cl} 0.08$ to 5.56 ), obesity (OR $1.14,95 \% \mathrm{Cl} 0.22$ to 5.99 ), age 0 to $<2$ years (OR 1.00 ), age 2 to $<5$ years (OR $1.30,95 \% \mathrm{Cl} 0.51$ to 3.32 ), age $\geq 5$ years (OR $0.92,95 \% \mathrm{Cl} 0.36$ to 2.33 ).

pH1N1, pandemic H1N1.

of children aged younger than 2 years, 2-4 years and 5 years and older, respectively, received antiviral therapy. While there was no difference in markers of disease severity, including ICU admission, mechanical ventilation and length of hospital stay between the two pandemic waves, there was a greater need for oxygen in children hospitalised during wave 1 . This difference only remained significant when restricting the analysis to those who did not receive antiviral therapy. This finding may reflect increased antiviral use directed at sicker children during wave 2 , while the mildest cases did not receive antivirals.

In the previous analysis of the first wave of $\mathrm{pH} 1 \mathrm{~N} 1$ in Toronto, asthma was a more significant risk factor for pH1N1 than for seasonal influenza. ${ }^{8}$ In this study, with more than three times the number of $\mathrm{pH} 1 \mathrm{~N} 1$ cases, we confirm the significance of asthma as a major risk factor; controlling for obesity and age (as a continuous variable), asthma was more likely to be present in hospitalised children with pH1N1 (OR 4.59, 95\% CI 1.42 to 14.81) than those with seasonal influenza A. In pH1N1 cases, asthma was associated with admission to ICU (OR 4.56, $95 \%$ CI 1.16 to 17.89$)$. This is in contrast to seasonal influenza $\mathrm{A}$ in which underlying asthma was not significantly associated with ICU admission (OR 2.47, 95\% CI 0.24 to 25.80$)$. We did not find that the severity of asthma was differentially associated with hospitalisation or ICU admission between $\mathrm{pH} 1 \mathrm{~N} 1$ and seasonal influenza A. While six (19\%) ICU admissions with pH1N1 had asthma (four mild, one moderate and one severe) compared to only one $(3 \%)$ (mild) ICU admission with seasonal influenza, the numbers were too small to be able to demonstrate a difference. In a large California study of 345 children hospitalised or who died of pH1N1, 31\% of hospitalised children and $34 \%$ of ICU and/or fatal cases had asthma. ${ }^{16}$ In Japan, $14 \%$ of non-severe cases of pH1N1 and $47 \%$ of severe cases had asthma, ${ }^{17}$ while a UK study found that asthma was present in $16 \%$ of children $<16$ years and $31 \%$ of adults. ${ }^{18}$ None of these studies examined severity of asthma or the differences between pH1N1 and seasonal influenza.
Immunological studies of severe $\mathrm{pH} 1 \mathrm{~N} 1$ cases have shown delayed expression of genes involved in the adaptive immune response, delayed viral clearance and increased levels of innate immunity mediators involved in the Th1 and Th17 response. ${ }^{19} 20$ Children with underlying asthma and other groups (such as pregnant women) thought to be at higher risk for severe $\mathrm{pH} 1 \mathrm{~N} 1$ disease $^{21-23}$ may have an altered immunological and inflammatory response to this virus resulting in increased disease severity. Interleukin 5 has been shown to be highly expressed in bronchial mucosa of patients with asthma, ${ }^{24}$ is a key player in eosinophilic inflammation $^{25}$ and has been found to be higher in serum of patients with pH1N1 with pneumonia than those without. $^{26}$ However, further research is needed to fully understand this association. While there is some evidence in adults that adjuvant corticosteroids in severe pH1N1 may increase mortality, ${ }^{27}$ the impact of inhaled corticosteroids in childhood asthma on $\mathrm{pH} 1 \mathrm{~N} 1$ severity is not known and this study was not designed nor powered to address this question.

Influenza vaccination coverage in children with asthma has been poor in many countries. ${ }^{28}{ }^{29}$ Some physicians remain sceptical of the need for vaccinating all children with asthma, ${ }^{30}$ while others tend to prioritise children with more severe asthma. ${ }^{31}$ Definitive data have been elusive. $^{32}$ Our findings suggest that physicians should ensure all children with asthma under their care have been vaccinated against pH1N1 (which is currently included in the standard seasonal influenza vaccine), regardless of severity of asthma, at least until randomised controlled trial data become available.

There are several limitations in this study including its retrospective design, single-centre site and inability to calculate population-based rates. The number of admitted patients with asthma, particularly to ICU, was small, and this may have hindered our ability to identify differences in risk based on severity. Additionally, we identified only the single most important underlying risk factor (with the exception of asthma, obesity and age, which were all collected for each patient), and thus, 
we were unable to explore interactions between risk factors in patients with multiple comorbidities. Our metrics of influenza severity-ICU admission and duration of stay-may be impacted by non-medical factors, such as bed availability. In regard to oxygen use, we did not have data on oximetry or criteria that were used by physicians to start or stop oxygen supplementation, and thus, it was difficult to determine the significance of the difference seen in wave 1 versus wave 2. In regard to oseltamivir use, we did not extract data on dosage, duration or when the medication was begun. However, the use of oseltamivir in this study was at the discretion of the attending physician and thus reflective of 'real life' use. It is possible that we did not identify all patients at our hospital with influenza (seasonal or pH1N1) due to false-negative testing or testing being performed at an outside hospital and not repeated at our institution; however, we expect both these cases to be very rare.

\section{CONCLUSIONS}

Risk factors for severe disease, specifically the presence of underlying asthma and increased age, differed between pH1N1 and seasonal influenza in children. There was no difference in overall disease severity. These results suggest that in future pandemics with new influenza strains, high-risk groups may be different than those traditionally considered as such. The reasons for the differing influence of asthma and age on host response to $\mathrm{pH} 1 \mathrm{~N} 1$ are not understood, and further study of the underlying mechanisms contributing to these differences may shed new light on the host-pathogen immunobiology of a pandemic strain of influenza virus. This study emphasises the need to ensure that all children with asthma have been vaccinated against $\mathrm{pH} 1 \mathrm{~N} 1$ influenza, regardless of the severity of their asthma.

\section{Author affiliations}

${ }^{1}$ Division of Infectious Diseases, Department of Pediatrics, The Hospital for Sick Children, The University of Toronto, Toronto, Ontario, Canada 2Division of Pediatric Medicine, Department of Pediatrics, The Hospital for Sick Children, The University of Toronto, Toronto, Ontario, Canada

${ }^{3}$ Division of Respiratory Medicine, Department of Pediatrics, The Hospital for Sick Children, The University of Toronto, Toronto, Ontario, Canada

${ }^{4}$ Division of Microbiology, Department of Pediatric Laboratory Medicine, The Hospital for Sick Children, The University of Toronto, Toronto, Ontario, Canada ${ }^{5}$ Department of Paediatrics, Leeds General Infirmary, Leeds, UK

Acknowledgements The authors thank all members of the microbiology laboratory at the Hospital for Sick Children for their hard work, excellence and dedication during the H1N1 pandemic. The authors also thank research nurses Suganya Lee and Kim Simpson for their significant contributions, graduate student Michelle Gaffey for statistical support and An Nguyen and Michelle Guanzon for their editorial assistance.

Contributors SM and DT conceived of and designed the study, conducted the analysis, interpreted the data and drafted the original manuscript. PP, MS, PS, SO, MB and UA contributed to the analysis and interpretation of data. All authors critically revised the article for important intellectual content and gave final approval of the version to be published.

Funding SM is a fellow of the Paediatric Scientist Development Program which is supported by grants from SickKids Foundation, Paediatric Chairs of Canada and the March of Dimes. DT is funded by SickKids Foundation and Institute of
Human Development Child and Youth Health, CIHR New Investigator Grant \#XG08-049R, CIHR Catalyst Grant \#CAT86860 and the University of Toronto Dean's Fund Pilot Study grant.

\section{Competing interests None.}

Ethics approval The SickKids Research Ethics Board approved and waived individual informed consent for this study.

Provenance and peer review Not commissioned; externally peer reviewed.

Data sharing statement There are not any additional unpublished data from the study that are available.

\section{REFERENCES}

1. Van Kerkhove MD, Vandemaele KA, Shinde V, et al; WHO Working Group for Risk Factors for Severe H1N1pdm Infection. Risk factors for severe outcomes following 2009 influenza A (H1N1) infection: a global pooled analysis. PLOS Med 2011;8:e1001053.

2. Iskander M, Booy R, Lambert S. The burden of influenza in children Curr Opin Infect Dis 2007;20:259-63.

3. Pickering LK, Baker CJ, Overturth GD, et al, eds. Red Book 2009 Report of the Committee on Infectious Diseases. 28th edn. Elk Grove Village, IL: American Academy of Pediatrics, 2009.

4. Libster R, Bugna J, Coviello S, et al. Pediatric hospitalizations associated with 2009 pandemic influenza A (H1N1) in Argentina. N Engl J Med 2010;362:45-55.

5. Plessa E, Diakakis P, Gardelis J, et al. Clinical features, risk factors, and complications among pediatric patients with pandemic influenza A (H1N1). Clin Pediatr (Phila) 2010;49:777-81.

6. Kumar S, Havens PL, Chusid MJ, et al. Clinical and epidemiologic characteristics of children hospitalized with 2009 pandemic $\mathrm{H} 1 \mathrm{~N} 1$ influenza A infection. Pediatr Infect Dis J 2010;29:591-4.

7. Engelhard D, Bromberg M, Averbuch D, et al. Increased extent of and risk factors for pandemic (H1N1) 2009 and seasonal influenza among children, Israel. Emerg Infect Dis 2011;17:1740-3.

8. O'Riordan S, Barton M, Yau Y, et al. Risk factors and outcomes among children admitted to hospital with pandemic $\mathrm{H} 1 \mathrm{~N} 1$ influenza. CMAJ 2010;182:39-44.

9. The Hospital for Sick Children. The Year in Review 2009-2010. The Annual Report of The Hospital for Sick Children. Toronto, Ontario: The Hospital for Sick Children, 2010.

10. Cutler J, Schleihauf E, Hatchette TF, et al; Nova Scotia Human Swine Influenza Investigation Team. Investigation of the first cases of human-tohuman infection with the new swine-origin influenza $A$ (H1N1) virus in Canada. CMAJ 2009;181:159-63.

11. StataCorp. Stata Statistical Software: Release 10. College Station, TX, 2007.

12. Centers for Disease Control (CDC). Defining Childhood Overweight and Obesity. 2010. http://www.cdc.gov/obesity/defining.html (accessed 1 Oct 2011).

13. Warren DW, Jarvis A, LeBlanc L, et al; CTAS National Working Group; Canadian Association of Emergency Physicians; National Emergency Nurses Affiliation; Association des Médecins d'Urgence du Québec; Canadian Paediatric Society; Society of Rural Physicians of Canada. Revisions to the Canadian Triage and Acuity Scale paediatric guidelines (PaedCTAS) (In English, French). CJEM 2008;10:224-43.

14. Bagdure D, Curtis DJ, Dobyns E, et al. Hospitalized children with 2009 pandemic influenza A (H1N1): comparison to seasonal influenza and risk factors for admission to the ICU. PLoS One 2010;5:e15173.

15. Public Health Agency of Canada. Clinical Recommendations for Patients Presenting With Respiratory Symptoms During the 2009-2010 Influenza Season. 2010. http://www.phac-aspc.gc.ca/ alert-alerte/h1n1/pdf/H1N1_DecisionTree_oct23_e.pdf (accessed 3 Dec 2010).

16. Louie JK, Gavali S, Acosta M, et al; California Pandemic (H1N1) Working Group. Children hospitalized with 2009 Novel influenza A (H1N1) in California. Arch Pediatr Adolesc Med 2010;164:1023-31.

17. Okada T, Morozumi M, Matsubara K, et al. Characteristic findings of pediatric inpatients with pandemic (H1N1) 2009 virus infection among severe and nonsevere illnesses. $J$ Infect Chemother 2011;17:238-45.

18. Nguyen-Van-Tam JS, Openshaw PJ, Hashim A, et al; Influenza Clinical Information Network (FLU-CIN). Risk factors for hospitalisation and poor outcome with pandemic A/H1N1 influenza: United Kingdom first wave (May- September 2009). Thorax 2010;65:645-51.

19. Bermejo-Martin JF, Martin-Loeches I, Rello J, et al. Host adaptive immunity deficiency in severe pandemic influenza. Crit Care 2010;14 R167. 
20. Bermejo-Martin JF, Ortiz de Lejarazu R, Pumarola T, et al. Th1 and Th17 hypercytokinemia as early host response signature in severe pandemic influenza. Crit Care 2009;13:R201.

21. Louie JK, Acosta M, Jamieson DJ, et al; California Pandemic (H1N1) Working Group. Severe 2009 H1N1 influenza in pregnant and postpartum women in California. N Engl J Med 2010; 362:27-35.

22. Creanga AA, Johnson TF, Graitcer SB, et al. Severity of 2009 pandemic influenza $A(\mathrm{H} 1 \mathrm{~N} 1)$ virus infection in pregnant women. Obstet Gynecol 2010;115:717-26.

23. Siston AM, Rasmussen SA, Honein MA, et al; Pandemic H1N1 Influenza in Pregnancy Working Group. Pandemic 2009 influenza A (H1N1) virus illness among pregnant women in the United States. JAMA 2010;303:1517-25.

24. Kotsimbos AT, Hamid Q. IL-5 and IL-5 receptor in asthma. Mem Inst Oswaldo Cruz 1997;92(Suppl 2):75-91.

25. Wang J, Young IG. Eosinophilic inflammation: mechanisms regulating IL-5 transcription in human T lymphocytes. Allergy 2007;62:1131-8.

26. Takano $\mathrm{T}$, Tajiri $\mathrm{H}$, Kashiwagi $\mathrm{Y}$, et al. Cytokine and chemokine response in children with the 2009 pandemic influenza $A$
(H1N1) virus infection. Eur J Clin Microbiol Infect Dis 2011;30:117-20.

27. Kim SH, Hong SB, Yun SC, et al. Corticosteroid treatment in critically ill patients with pandemic influenza A/H1N1 2009 infection: analytic strategy using propensity scores. Am J Respir Crit Care Med 2011;183:1207-14

28. Centers for Disease Control and Prevention (CDC). Influenza vaccination coverage among children with asthma-United States, 2004-05 influenza season. MMWR Morb Mortal Wkly Rep 2007;56:193-6.

29. Rance F, Chave C, De Blic J, et al. Low influenza vaccination coverage in asthmatic children in France in 2006-7. Euro Surveill 2008;13:19016.

30. Bueving HJ. Is influenza vaccination in asthmatic children helpful? Clin Exp Allergy 2006;36:21-5.

31. Dombkowski KJ, Leung SW, Clark SJ. Physician perspectives regarding annual influenza vaccination among children with asthma. Ambul Pediatr 2008;8:294-9.

32. Cates CJ, Jefferson TO, Rowe BH. Vaccines for preventing influenza in people with asthma. Cochrane Database Syst Rev 2008;(2): CD000364. 